\title{
Negociando la inclusión al mercado de consumo Los programas de transferencias condicionadas de dinero y el orden familiar
}

\author{
Negotiating inclusion into the consumption market \\ Conditional cash transfer programs and family order
}

\author{
Ariel Wilkis* \\ Martin Hornes**
}

\begin{abstract}
Resumen: Este trabajo explora dos procesos que, habitualmente, la agenda de investigaciones sobre sociología económica ha abordado de forma separada: los procesos de financiarización del consumo y la monetización de las políticas sociales en los sectores populares. A través de un trabajo etnográfico realizado en el área metropolitana de la ciudad de Buenos Aires, sugerimos el abordaje de una nueva infraestructura monetaria del mundo popular donde distintas piezas del dinero (finanzas y políticas sociales) se mutualizan y muestran una nueva realidad económica de los sectores populares.
\end{abstract}

Palabras claves: Finanzas. Consumo. Políticas sociales. Infraestuctura monetaria.

\begin{abstract}
This paper explores two processes that agendas of economic sociology research normally addresse separately: the processes of financialization of consumption and monetization of social policies in the popular sectors. Through ethnographic work carried out in the Buenos Aires metropolitan area, we suggest looking into the new monetary infrastructure of the popular world where different monetary segments converge and (finance and social policy) and show the new economic reality of the popular sectors.
\end{abstract}

Keywords: Finances. Consumption. Social policies. Monetary infrastructure.

* Doctor en Sociología por la Universidad de Buenos Aires (UBA, Buenos Aires, Argentina) y la Ecole de Hautes Etudes en Sciences Sociales (EHESS, Paris, Francia), investigador adjunto Conicet y co-director del Centro de Estudios Sociales de la Economía (Cese), Instituto de Altos Estudios Sociales (Idaes) de la Universidad Nacional de San Martín (Unsam) en San Martín, Argentina<ariel.wilkis@googlemail.com>.

**Magister en Antropología Social por la Universidad Nacional de San Martín y doctorando en Sociología en la misma universidad <m_hornes@hotmail.com>.

Civitas, Porto Alegre, v. 17 , n. 1, p. 61-78, jan.-abr. 2017

Exceto onde especificado diferentemente, a matéria publicada neste periódico 


\section{A modo de introducción}

"Ya tengo que pagar mis cuentitas" menciona Yoli, lo que significa que debe trasladarse esa misma tarde hasta el centro de la ciudad y dirigirse a los locales de préstamo personal para cancelar sus deudas: "ahorita debo salir ya para pagar la obra, quiero terminar mi casita". Preguntamos si acaso debía mucho dinero: "ah pues que ya es mucho... casi 30 mil pesos ahora nomás". Rápidamente, Yoli nota nuestra sorpresa por la magnitud del monto, por lo que extiende su relato detallando las estrategias familiares que garantizan las formas de pago:

ahorita es mucho interés. Lo que pasó es que ya tuve muchos atrasos y fueron muchos pedidos de mis hijos: para muebles, materiales y otras cosas de ellos. Pero este mes ya hablé con todos mis hijos, saben que deben colaborar. Fueron sus pedidos y deben esforzarse. Mi hija separó su platita de los planes de los chicos. Ya es hora de salir.

Cuando recogimos este testimonio de Yoli, las consecuencias de las políticas neoliberales de los años 90' eran reconocibles en los barrios populares de Buenos Aires, pero no eran los únicos signos visibles. Con la asunción del presidente Néstor Kirchner en el año 2003, se produce un viraje en la orientación de la política económica argentina marcada por el cuestionamiento del neoliberalismo y sus consecuencias negativas para los más pobres. Este proceso encuentra continuidad en el gobierno de Cristina Kirchner, que asume la presidencia en el año 2007.

En Argentina, durante las presidencias de los Kirchner, se desarrolló una amplia política de transferencias de recursos hacia los más pobres que permitió aumentar la participación de los sectores excluidos en el mercado de consumo. Junto a sus pares de Bolivia (Evo Morales), Venezuela (Hugo Chavez), Brasil (Luiz Inácio Lula da Silva y Dilma Rousseff), Ecuador (Rafael Correa) y Uruguay (José Mujica), definieron la "inclusión al mercado" como un paradigma de bienestar para los más pobres. ${ }^{1}$ Esta concepción política se basaba en una nueva interpretación sobre el dinero público que circula hacia los sectores más relegados, que replantea el rol del mercado en relación a estos sectores. Las políticas de gobierno significaron un pasaje desde una "política

\footnotetext{
${ }^{1}$ Para los analistas (Cameron y Herschberg, 2010; Levitsky y Roberts, 2011) dichos gobiernos formaban parte del "giro hacia la izquierda" que experimentaron los países de la región en los años 2000 (Brasil, Bolivia, Ecuador, Uruguay y Venezuela).
} 
de contención" donde el dinero era transferido para prevenir un deterioro de sus condiciones de vida, a una "política de rehabilitación" donde se enmarca el dinero en el uso positivo para incluirlos en el mercado y para reactivar el conjunto de la economía (Wilkis, 2017).

En la agenda de estos gobiernos, el aumento del "consumo popular" fue tomado como una bandera de éxito de sus políticas sociales y económicas. El impacto de estas políticas se refleja en el hecho de que los hogares más pobres aumentaron cuatro veces su ingreso mensual medido en valores corrientes entre 2004 y 2013. En cambio, los hogares más ricos lo hicieron alrededor de 2,6 veces. Esta tendencia tiene su correlato en la reducción de la desigualdad frente al consumo: para los habitantes de Buenos Aires la brecha total de consumo medio per capita entre ricos y pobres disminuyó de 7,3 a 5,0.

En este artículo exploramos dichos procesos macro-sociales e institucionales a la luz de la experiencia de personas como Yoli y su familia. Nuestro propósito es comprender aquello que estas narrativas políticas y las estadísticas no llegan a captar y que, de alguna manera, es la condición de lo que ellas reflejan a nivel del discurso y de los números públicos. Como nos permite advertir la narración que abre este articulo, el proceso de "inclusión al mercado de consumo" a través de los programas de transferencia monetaria condicionada (TMC) está atravesado de negociaciones y tensiones entre los integrantes de familias como las de Yoli.

A través de investigaciones que realizamos los últimos años sobre los usos del dinero en el mundo popular, llevamos adelante una sociología que analiza la dimensión moral del dinero como una entrada privilegiada para comprender las relaciones de poder (Wilkis, 2017). Cómo lo demostraremos en este texto, el uso del dinero proveniente de los programas de transferencia monetaria condicionada para participar en el mercado de consumo es un laboratorio sociológico crucial para expandir esta interpretación y, al mismo tiempo, una clave novedosa de su interpretación. En este sentido, proponemos articular la sociología de los dineros múltiples con la sociología del poder de Pierre Bourdieu. El concepto de capital moral es una herramienta central para iluminar las conexiones entre dinero, moral y poder que se pone en juego a través de los programas de transferencia monetaria condicionada.

En este artículo proponemos comprender las relaciones de poder que le dan forma al universo familiar a través de la dimensión moral del dinero. La circulación de dinero ayuda a producir la jerarquía entre los miembros de las familias (entre padres e hijos, maridos y esposas). Retomar estas perspectivas nos permitirá analizar cómo las relaciones de poder familiares son alteradas, modificadas o desafiadas a partir de la expansión del dinero proveniente de 
los programas de transferencia monetaria condicionada. Reconstruyendo prácticas monetarias sumamente vinculadas a la presencia de diferentes dineros distribuidos por el estado, exploramos cómo el orden social familiar está enraizado en un orden monetario (Wilkis, 2017).

Este artículo reúne hallazgos de distintos trabajos etnográficos que hemos realizado en barrios populares de las localidades de La Matanza y Avellaneda, dentro del primer cordón del área metropolitana de Buenos Aires (Amba), y en barrios de la zona sur de la Ciudad Autónoma de Buenas Aires (Caba) desde el año 2008 hasta la actualidad.

El trabajo se organizará de la siguiente manera. En la primera parte, desarrollamos la perspectiva teórica para analizar las conexiones entre dinero, moral y poder. En la segunda parte, describimos la expansión de los programas de transferencia monetaria condicionada como tecnologías monetarias globales y su peso en las economías domesticas en los hogares de las clases populares en Argentina. En la tercera parte, introducimos dos escenas etnográficas centradas en la reconstrucción de hogares titulares de transferencia monetaria condicionada. Este abordaje nos permitirá describir cómo se organizan los dineros provenientes de las políticas sociales en ambos hogares, observando cómo las piezas del dinero inciden en tal organización y clasificación, estableciendo jerarquías morales y relaciones de poder movilizadas a partir de disputas intergeneracionales y construcciones sociales del género. Para finalizar, realizaremos algunas reflexiones sobre el impacto de las transferencias monetarias condicionadas en la vida familiar como una perspectiva de análisis del enraizamiento del dinero público en la vida cotidiana de los sectores populares y sus posibilidades de participar en el mercado de consumo.

\section{Dinero, moral y poder: una perspectiva sociológica}

El renacimiento de una sociología del dinero desde la década del ochenta puede ser interpretado como parte de un movimiento más global de cuestionamiento a las narrativas de un dinero universal y homogéneo. Desde la historia, (Kuroda, 2008), la economía (Theret, 2007), la antropología (Guyer, 2012) y la sociología (Blanc, 2009; Dodd, 2014; Zelizer, 2011), se ha elaborado una narrativa centrada en la multiplicidad de monedas que pone en cuestión la figura del dinero moderno pensado como "equivalente general" (Marx, 1976), como "medio de todos los medios" (Simmel, 1996) o como "moneda de propósitos generales" (Polanyi, 2001).

Nigel Dodd (2014) recientemente ha sintetizado este desplazamiento indicando que si la sociología clásica se preocupó por mostrar 
cómo el dinero moldea la cultura, la sociología contemporánea realiza el movimiento inverso: muestra cómo el dinero es formateado por la cultura. Se trata de interpretar a la cultura o la moral como propiedades intrínsecas al dinero y no como atributos accidentales que pueden ser prescindibles al momento de comprender cómo actúa en la vida social. De esta manera, el viraje conceptual consiste en entender el capital moral no como un atributo externo del dinero sino como una de sus propiedades intrínsecas. Este desplazamiento ensambla la perspectiva sobre el poder de Pierre Bourdieu con el concepto de dineros múltiples presente en la sociología de Viviana Zelizer.

El mayor aporte de Viviana Zelizer es mostrar que el dinero es un poderoso agente socializador. La autora narra cómo las personas están comprometidas en atribuir medios de pagos específicos (monedas especiales) a diferentes categorías de vínculo social (Zelizer, 2011). Zelizer hizo también hincapié en este aspecto cuando elaboró el concepto de circuito de comercio (Zelizer, 2010). La existencia y permanencia de los circuitos dependen del trazado de fronteras entre sus miembros y las personas que no pertenecen. El uso de monedas especiales juega un rol crucial para establecer estas fronteras. Más recientemente, Zelizer (2012) propuso el termino "trabajo relacional" para designar este esfuerzo de las personas para hacer coincidir (to match) significados morales y medios pagos de tal forma de hacer viable una interacción o relación social prolongada. Una lectura por cada uno de estos diferentes trabajos permite identificar una constante: para Zelizer el dinero siempre funciona midiendo, evaluando y comparando moralmente a las personas y sus vínculos sociales.

A la luz de estos análisis, la sociología de Zelizer invita a repensar al dinero desde una propiedad muy especial: las monedas no solo funcionan como medios de pago, de intercambio, reserva de valor y unidad de cuenta abstracta, sino que también operan como unidades de cuenta moral. Si la sociología clásica (Marx y Simmel) encontraba en la conmensurabilidad abstracta del dinero la posibilidad para que este sea el "gran nexo" entre las personas, esta nueva propiedad del dinero produce este nexo a través de una especie de conmensurabilidad moral. Las personas son medidas, evaluadas y jerarquizadas moralmente a través del tipo de dinero que se les asocia. Conectamos esta propiedad del dinero con el concepto de capital moral. En este artículo entendemos el concepto de capital moral como otra subespecie de capital simbólico y, en una extensión de la propuesta de Bourdieu (1997), esgrimimos su capacidad para ayudar a comprender la dinámica de reconocimiento y sus efectos de distinción moral. 
A través de las obligaciones se hace legible las virtudes de las personas, y estas virtudes funcionan como poderes. Por este motivo el componente moral del capital moral esta definido por el reconocimiento de virtudes evaluadas y juzgadas a través de ideas de obligación social. A través de esta perspectiva analizamos la expansión de los programas de transferencia monetaria condicionada y su arraigo en la vida cotidiana de las familias de sectores populares.

\section{La expansión de los programas de transferencia monetaria condicionada: las nuevas tecnologías monetarias globales}

Las primeras implementaciones de programas de transferencia monetaria condicionada en la región de América Latina datan del año 1997 y refieren al lanzamiento del programa Progresa (Programa de Educación, Salud y Alimentación) dirigido a las comunidades rurales pobres de México. Considerado en los documentos de los organismos internacionales y por los saberes expertos como un programa destinado a invertir en el capital humano de las familias pobres, el programa Progresa introduce en la región la noción de transferencias de dinero en efectivo bajo la premisa del cumplimiento de condicionalidades.

Tal como han de estructurarse los programas de transferencia monetaria condicionada en los países de América Latina, el Progresa introduce tres condicionalidades centrales sobre las transferencias monetarias dirigidas a los hogares pobres: 1) sobre la asistencia escolar de los menores pertenecientes al hogar; 2) sobre la atención primaria de la salud (controles sanitarios y de vacunación) y; 3) sobre aspectos referidos a la nutrición. Estas premisas se constituirán como los ejes fundamentales de las transferencias monetarias condicionadas -"a dual policy" siguiendo la denominación experta- con efectos de corto plazo (short time) y largo plazo (long time): proveer ingresos a los hogares más necesitados incentivando el consumo de bienes básicos e invirtiendo en el capital humano de los menores para quebrar la pobreza que se transmite de forma intergeneracional (Cruces et al., 2008).

Rápidamente Progresa se transforma en "uno de los casos más analizados y mejor evaluados en el ámbito de las transferencias monetarias condicionadas de América Latina" (Villatoro, 2005, p. 96). Su implementación pone en movimiento una infinidad de evaluaciones de impacto -tanto cuantitativas como cualitativas-llevadas a cabo por expertos en políticas sociales vinculados a organismos internacionales como el Banco Interamericano de Desarrollo (BID) o el Banco Mundial (BM). En una multiplicidad de informes, reports y papers, se resaltarán los alcances en materia de los atributos más importantes 
de las transferencias monetarias: la focalización, la intersectorialidad, el empoderamiento de las mujeres, y la corresponsabilidad (Skoufias y Parker, 2001; Banco Mundial, 2009).

Durante el año 2001, y bajo la presidencia de Vicente Fox, el Progresa pasó a llamarse programa Desarrollo Humano Oportunidades y amplió su alcance a las poblaciones urbanas. Se trató de una transformación sustancial cuando observamos que, de un contexto rural donde la cobertura alcanzaba a 300 mil familias, a principios de 2002, la intervención social llegaba a más de 2 millones de hogares de todo el país. Durante el transcurso del año 2014, la política de transferencias de ingreso mexicana recibió una nueva denominación: Prospera Programa de Inclusión Social, incorporando en sus líneas de intervención una batería de transferencias diferenciadas y específicas según grupo etario y género de los distintos miembros de las familias beneficiarias. $^{2}$

La trayectoria del programa emblema mexicano inició lo que los expertos en la temática señalan como "la oleada latinoamericana" (Cecchini y Madariaga, 2011) o la denominada "revolución silenciosa" en la lucha contra la pobreza en América Latina (Barrientos, Hulme y Hanlon, 2008). Durante el año 2002 se originó en la República de Chile el programa Chile Solidario, compuesto por una transferencia de dinero focalizada en hogares de extrema pobreza. En el año 2003, el gobierno federal del Brasil lanzó el programa Bolsa Familia. A lo largo de los años 2005 y 2006, surgieron y se consolidaron en la región otros programas con características similares. Desde el año 2005 se destacan la presencia del Programa Juntos de Perú, en la República del Paraguay la implementación del programa Tekoporá destinado a familias pertenecientes a las comunidades rurales. Por su parte, la República de Bolivia inició un ciclo de transferencias con el Bono Juancito Pinto en el año 2006, y actualmente implementa el Bono Madre Niña - Niño Juana Azurduy, los cuales intervenían en las áreas de educación y salud respectivamente. A partir del año 2008, la República Oriental del Uruguay puso en funcionamiento el programa de transferencia monetaria condicionada. Asignaciones familiares, con características similares a los anteriores (Stampini y Tornarolli, 2012).

En la República Argentina, asistimos a una conversión similar a la observada en la región. En un escenario de crisis económica/financiera y, con un nivel de desocupación que alcanzaba a más del $20 \%$ de la población del país, durante el año 2001 surge el primer programa de transferencia monetaria

\footnotetext{
2 Para más información sobre aspectos programáticos se puede consultar la página web del programa: <www.prospera.gob.mx/swb/es/PROSPERA2015/Quees_PROSPERA>.
} 
condicionada destinado a las poblaciones vulnerables desocupadas bajo la denominación Plan Jefes y Jefas de Hogar Desocupados. En sintonía con los cambios acontecidos en la región, a partir del año 2004 se despliegan una serie de intervenciones que dan lugar al surgimiento de distintos programas: el Plan Familias por la Inclusión Social, el Plan Manos a la Obra, y el Plan de Seguro de Capacitación y Empleo. Incluso a inicios de 2008, el emblemático Plan Vida radicado en la Provincia de Buenos Aires e impulsado desde el año 1994, transforma su estrategia de intervención suplantando la entrega de alimentos por una suma de dinero según la cantidad de hijos por beneficiario.

Durante el año 2009 asistimos al surgimiento de dos programas de envergadura en términos de transferencia monetaria condicionada. Nos referimos al Programa Ingreso Social con Trabajo Argentina Trabaja bajo la dependencia del Ministerio de Desarrollo Social de la Nación, y a la Asignación Universal por Hijo para la Protección Social (AUH) bajo la dirección de la Administración Nacional de la Seguridad Social (Anses, 2012). Desde 2014, el Ministerio de Trabajo implementa el Programa de Respaldo a Estudiantes Argentinos (Progresar), dirigido a jóvenes de 18 a 24 años que no trabajen o lo hagan de forma informal, con el objetivo de que finalicen sus estudios o se formen en oficios u orientación laboral.

Podríamos seguir enumerando una serie de programas de transferencia monetaria condicionada que se encuentran en ejecución y bajo otras dependencias estatales. Sin embargo, nos interesa resaltar el grado de institucionalidad y el nivel de cobertura que estas políticas han alcanzado. Sólo contemplando algunas de las prestaciones monetarias de mayor magnitud, podemos apreciar un número de titulares que supera los 5 millones de personas. Si contemplamos el crecimiento exponencial que mostraron un en la última década los programas de pensiones de tipo no contributivas (invalidez, vejez, leyes especiales, etc.), el número podría ascender a más de 6 millones de beneficiarios (Cepal, 2016).

En la actualidad, el enraizamiento del dinero estatal en los hogares pobres se convierte en una tecnología monetaria global. Los estados de distintas partes del mundo y bajo distinto signo político han incorporado estos instrumentos monetarios para otorgarle una impronta innovadora a las políticas sociales (Lavinas, 2013). Dada esta centralidad cuantitativa le corresponde ser complementada con una mirada cualitativa del dinero de las transferencias monetarias condicionadas, perspectiva que desarrollaremos a través de un análisis de la dimensión moral del dinero proveniente del estado, como entrada para comprender las relaciones de poder que están siendo redefinidas a nivel de las familias. 


\section{Cuidar el rebaño y caminar la calle}

Conocimos a Marcelo y a Cristina hacia fines del año 2008. Ambos promedian los 50 años de edad y viven en un barrio en plano proceso de urbanización próximo al cementerio de Avellaneda. En ese momento se encontraban desocupados y el presupuesto del hogar contaba con ingresos variables provenientes de distintas changas que realizaba Marcelo.

Marcelo había trabajado en una de las curtiembres del barrio por más de 25 años. Aproximadamente desde el año 2005 había abandonado ese trabajo porque contrajo la fiebre reumática, una enfermedad propia de la exposición a las precarias condiciones de trabajo en que se realizaba la actividad. Cristina no tenía una trayectoria laboral muy extensa. Durante algunos años había trabajado como empleada doméstica en una casa de familia en la zona de Bajo Flores, en la ciudad de Buenos Aires. Luego trabajó un tiempo desde su casa porque un vecino del barrio le llevaba ciertos materiales para armar veladores de luz. Más tarde decidieron que "lo mejor era encargarse de los chicos": "nos daba miedo que pasen tanto tiempo solos o estando nosotros fuera de la casa", afirmaba.

La familia la completaban Ezequiel y Sabrina, de 26 y 22 años respectivamente, y Ayelén, de 16 años de edad. Ayelén asistía a la escuela secundaria $\mathrm{y}$, a contra turno del colegio, participaba en un programa de transferencias monetarias dirigido a adolescentes en situación de vulnerabilidad social. ${ }^{3}$ Los dos mayores ya no vivían con ellos, pero seguían dependiendo de la ayuda económica de sus padres para llegar a fin de mes.

Marcelo siempre afirmaba que sabía cómo cuidar a su rebaño, la cual no resultaba una simple frase, sino que tenía muchos significados interesantes que guardaban relación con la forma de organizar la economía del hogar.

"Cuidar el rebaño" refería a una serie de prácticas económicas que Marcelo movilizaba para organizar el presupuesto del hogar: "hay que moverse, caminar la calle porque acá el que no labura es porque no quiere", agregaba. Dentro de esas estrategias de "caminar la calle" se encontraban las "changas" como bicicletero o los trabajos de poda en las proximidades de Avellaneda:

En la calle hay plata. Yo los viernes me voy al galpón de chatarra ahi cerca de (Villa) Corina. Yo compro cuadros de bicicleta a

\footnotetext{
${ }^{3}$ Bajo la denominación "Jóvenes" nos referiremos a un programa social de transferencia monetaria condicionada de alcance provincial destinado a adolescentes de 12 a 21 años que se encuentran en situación de vulnerabilidad social. Para más referencias: Hornes (2014).
} 
16 pesos el kilo, las pinto acá en casa, y después las termino de armar en la bicicletería de un amigo. El otro día vendi una a 350 (pesos). Si vos necesitas plata salís a la calle y algo para hacer encontrás. El otro día me fui a caminar por allá por (Villa) Domínico con mi bolsito de herramientas. Yo camino, me fijo, viste, la gente siempre necesita que le hagan algo. Vi una casa que tenía los árboles para podar, le toqué y salió una viejita y le pregunté si quería que se los corte un poco. Estuve dos horas y me volvi a mi casa con 80 pesos. Todo suma.

Además de estas "changas" que Marcelo sabía buscar en la calle tenía toda una serie de estrategias para esconder dinero en distintos lugares de la casa. Una tarde en que estábamos conversando, Cristina se levantó de la mesa de la cocina para ir al baño. Marcelo espero unos segundos hasta que ella cerrara la puerta del mismo, nos miró, y en voz baja mencionó: "sigan hablando como si nada". De pronto se levanto, saco un billete de 100 pesos que estaba doblado en la parte de atrás de su porta documentos, estiro su brazo hasta una cómoda cercana a la mesa, y lo introdujo por la parte de atrás de uno de los parlantes del equipo de música. Rápida y sigilosamente volvió a ocupar la silla en que se encontraba antes que Cristina saliera del baño.

Días más tarde tuvimos la posibilidad de retomar la situación anterior: "siempre hay que tener un canuto", respondió Marcelo sin vacilar siquiera un segundo. "Tener un canuto", "buscarle la vuelta, el lugar... como un rompecabezas", "separar" o "sacar de la cancha", eran una de las tantas maneras en que Marcelo presentaba las distintas formas de acceder al dinero o clasificar estrategias de ahorro para momentos en los que se necesitara disponer de efectivo. "Yo no sé de dónde saca, pero él siempre tiene", nos decía Cristina: "acá tenés gorda, 100 pesos. Con Marcelo pasamos mucha necesidad, pero nunca nos faltó para comer".

En el año 2011 la situación económica de la familia mejoró notablemente. Marcelo y Cristina pasaron a formar parte del Programa Inclusión Social con Trabajo - Argentina Trabaja dependiente del Ministerio de Desarrollo Social de la República Argentina. ${ }^{4}$ Ambos cumplían con cuatro horas diarias de trabajo en barrios aledaños al suyo, Marcelo realizando trabajos de desmalezamiento y Cristina de barrido en la vía pública o de limpieza en las instituciones del municipio o en las escuelas estatales.

\footnotetext{
${ }^{4}$ Se trata de un programa de transferencia monetaria con contraprestación laboral dirigido a personas en situación de vulnerabilidad social que se encuentren desocupadas y no cuenten con ingresos formales $<$ www.desarrollosocial.gob.ar/ingresosocialcontrabajo $>$
} 
La incorporación de ambos al programa de transferencias monetarias tuvo un efecto transcendental en el presupuesto del hogar ya que no sólo lograban duplicar o triplicar el monto del mismo sino, también, les permitía contar con un ingreso estable y flujos de dinero constantes. Ante esta situación imaginamos que Marcelo iba a abandonar sus búsquedas de dinero en la calle, pero, por el contrario, decidió reformular la estrategia para "cuidar su rebaño".

Una tarde, mientras conversábamos en ausencia de Cristina, Marcelo arrojó otra de sus célebres frases: "la mujer en la casa y el hombre en la calle... para que no te metan las guampas". Lo que en principio podría parecer un comentario gracioso sobre las relaciones de pareja y la fidelidad, escondía algo más: "no te digo que me molesto, pero...". Decidió continuar su relato aludiendo que "un poco me preocupa por la Ayelén que todavía es chica", refiriéndose a las horas de trabajo que Cristina cumplía por las mañanas en alguna dependencia municipal y, por ende, de su ausencia en el cuidado del espacio doméstico y la crianza de su hija. Por si quedaban dudas, añadió: "vamos a ver si nos organizamos así o volvemos como antes". Posición que, de forma directa, revelaba la sensación de amenaza de su rol de omnipresente proveedor.

\section{Cuando el dinero no es justo}

Patricia tiene unos 40 años de edad aproximadamente. Ella vive junto a su hija, Natalia de 15 años de edad y con su actual pareja, Ezequiel. Con ellos también conviven los dos hijos varones que Ezequiel tuvo con su anterior pareja: Nicolás y Santiago de 18 y 14 años de edad, respectivamente. Conocimos a Patricia y a su familia gracias al contacto de otros vecinos del barrio a principios de 2011 .

El presupuesto del hogar se nutre de los trabajos informales de Patricia y Ezequiel. Patricia trabaja hace aproximadamente dos años en una mercería del centro de Avellaneda mientras que Ezequiel trabaja con su propio auto como remis en una de las pocas agencias del barrio. Patricia "está cansada" de la mercería porque la tienen en "negro", hace tiempo no le aumentan el sueldo y, al final, ella "entro con la promesa de estar en blanco... y a las palabras se las lleva el viento". Su disgusto se eleva más todavía cuando habla del trabajo de Ezequiel: "él suponía que iba a ser algo temporario y termino siendo un clavo. Gana poca plata, pasa mucho tiempo sentado en la vereda mirando la calle y, encima, llega a cualquier hora", agrega Patricia con cierto enfado.

Patricia se define como una "laburadora de toda la vida. Mis viejos me enseñaron eso porque es así, somos pobres, no te queda otra que laburar para 
vivir". Como tantas de las historias que conocimos en el barrio, los padres de Patricia migraron desde el interior buscando en la capital del país trabajo y progreso familiar. Solíamos conversar con Patricia luego del mediodía, en la franja horaria en que ella estaba en su casa porque la mercería se encontraba cerrada hasta las cinco de la tarde.

Desde nuestros primeros encuentros Patricia se dio cuenta que nosotros queríamos "hablar de guita”: "yo les entendi eso... que querían hablar de guita”. La definición nos pareció perfecta $\mathrm{y}$, día tras días, hablábamos de los ingresos del hogar, de cómo organizaban el dinero, de quienes eran los encargados de pagar que cosas, de las tarjetas de crédito prestadas o los créditos personales que sacaban, de sus "peleas con Natalia" y demás cuestiones.

Con el tiempo nos dimos cuenta que el tópico las "peleas con Natalia" resultaba central, no sólo porque pasábamos mucho tiempo hablando de ellas y "sus diferencias", sino porque tuvimos la posibilidad de conversar personalmente con Natalia. Una de esas tardes, Patricia no volvió a su casa entre las horas en que la mercería se encontraba cerrada. Casualmente en la casa se encontraba Natalia, quien nos reconoció como los que "íbamos siempre a la tarde".

Aprovechamos el intercambio con Natalia para contarle que, en realidad, estábamos conversando con distintos vecinos del barrio porque nos interesaba conocer la situación económica de algunas familias y sus estrategias para mantener los gastos del hogar. Nos sorprendió la reacción de Natalia: “y bueno... le pueden preguntar a mí mamá por qué hace meses que estoy en el programa Jóvenes y no me deja usar la plata”, arrojó con cara de desagrado. Según su relato, hacía varios meses que no podía disponer del uso del dinero porque Patricia lo utilizaba para otro tipo de gastos del hogar:

Estoy cansada de que todos los meses me hagan lo mismo. Me piden la plata, me dicen que en unos días me la devuelven, y después pasa el mes y no recupero nada. Que sea para las plantillas que Nico necesita no me molesta, pero me da mucha bronca que Ezequiel sacó un equipo de música nuevo, y no tiene ni para las plantillas de Nico ni para pagar las cuotas. Y mi mamá... mi mamá no le dice nada. Cumplo con todo: no falto nunca a la escuela, hago las tareas y voy siempre al Jóvenes... no es justo.

La inesperada escena no duro más de dos o tres minutos. Estábamos como sorprendidos con el descargo de Natalia, pero sabíamos que era una oportunidad para seguir conversando con Patricia. El intercambio también 
nos servía para sospechar que las "peleas" y "diferencias" entre Natalia y Patricia guardaban algún tipo de relación con el uso del dinero proveniente de las transferencias monetarias condicionadas.

Pasados unos días volvimos a conversar una tarde con Patricia. Ese día ella estaba "contenta": "me dijeron que, por ahí, el mes que viene, me dan el aumento en la mercería". Si bien no sabía de cuanto dinero se trataba con exactitud, estaba contenta de que le "hubiesen dado bola", en alusión a la demanda que ella planteaba desde hacía tiempo a los dueños del local. Nos alegramos por ella y Patricia agregó: "la que se va a poner contenta es Natalia... que le debo una plata a ella también". Tímidamente mencionamos que algo de aquella situación conocíamos, a lo que Patricia respondió: "si, ya sé. Yo la conozco a mi hija, no da puntada sin hilo, les fue con el cuento de las plantillas ortopédicas", en relación al dinero proveniente del programa que había sido utilizado para comprar las plantillas para uno de los hijos de Ezequiel:

Yo me hago cargo de mi parte, pero ella no. Claro que a veces necesito arreglármelas con esa plata para llegar a fin de mes. Reconozco que es algo de ella también, pero yo nunca le pido nada, entonces tiene que empezar a aprender que a veces hay que dar una mano en la casa también.

Continuó varios minutos con palabras similares, pero lo que nos resultó más inquietantes es que existían distintas situaciones que entrelazaban al dinero proveniente del Jóvenes: "No es sólo las plantillas de Nicolás. Es Ezequiel que el trabajo no le rinde como esperábamos... pero es ella también”. Patricia estaba enojada con Natalia porque tenía "un nuevo noviecito: ese Jorge que todo el mundo sabe que anda vendiendo droga para el padre, todo el día en la motito de acá para allá. Yo no me chupo el dedo", agregaba.

De estar "contenta" Patricia parecía ahora acongojada. Aseguraba que se trataba de "muchas cosas": "yo también fui chica como ella. No quiero que corra riesgos, quiero que termine de estudiar y que pueda ser alguien en la vida". No sólo le preocupaba la situación de Natalia sino también su propia situación: "yo no le puedo decir a ella todo lo que pienso... que Ezequiel me ayuda poco y nada... que la plata de su trabajo son para sus cosas". Las "peleas" y "diferencias" que parecían tener como centro al dinero proveniente de la participación de Natalia en el Jóvenes, implicaba tensiones entre distintos tipos de relaciones: "no me queda otra que lidiar con ella. No puedo decirle que su padrastro no se hace cargo de nada, ni siquiera de sus propios hijos. Es la que me toca a mi", sentenciaba Patricia. 


\section{Moral y poder en la vida familiar}

En distintas aproximaciones etnográficas hemos analizado los significados plurales que adquiere el dinero transferido a partir de las políticas sociales. Nuestros hallazgos nos permiten señalar que, lejos de las definiciones técnicas que los saberes expertos en políticas sociales intentan imprimirle al dinero proveniente de las transferencias monetarias condicionadas, los hogares negocian sus significados movilizando valores personales, sociales y familiares asociados a dimensiones sociales del género e interpretaciones intergeneracionales sobre el dinero (Hornes, 2015 y 2014).

"El hombre en la calle y la mujer en la casa" afirmaba Marcelo para delimitar el lugar que entendía por excelencia del hombre, mientras que "la casa" parecía ser el lugar donde salvaguardar a la familia y, por ende, el espacio que debe quedar bajo la órbita y el cuidado de la figura femenina. Una frase que se da en un contexto familiar particular considerando la incorporación de ambos al Programa Argentina Trabaja y, por lo tanto, ante una situación de paridad en sus ingresos vía políticas sociales de transferencia monetaria. Ante la paridad de ingresos Marcelo ve amenazada su posición en el lugar de la "casa" como único e incuestionable proveedor, situación que lo lleva a emprender una estrategia de desjerarquización y jerarquización de distintas piezas de dinero. Es decir, aludiendo a la desprotección y a los peligros que pueden acontecer en el hogar bajo la ausencia de Cristina, Marcelo promueve una desjerarquización del dinero que ella percibe a través de su participación en el programa de transferencia monetaria.

Marcelo cerraba su exposición mencionando la frase "volvemos como antes". Palabras que, de alguna manera, implican volver a jerarquizar el dinero que el obtenía a través de sus inagotables búsquedas de trabajo en "la calle". En resumidas cuentas, jerarquizar la pieza de dinero ganado por medio del trabajo implica volver a un orden monetario que no altere el orden social familiar, su posición de poder y capital moral.

La situación de Patricia nos puede servir para forjar una lectura interpretativa similar. La escena etnográfica que la tiene como protagonista deja en claro que ella se encuentra en una marcada situación de desigualdad frente a Ezequiel, dado que este último "hace sus cosas con su plata", lo que revela una total independencia del dinero que consigue trabajando como remisero. En ese contexto de situación, Patricia decide que la mejor estrategia es "lidiar" con Natalia. 
"Lidiar" con Natalia se traduce como la posibilidad que tiene Patricia de "lidiar" con una situación menos conflictiva o incluso favorable. En primer lugar, las controversias que se pueden generar ante el uso del dinero proveniente del programa de transferencia monetaria condicionada en que participa su hija, parecen de menor índole frente a la idea de desafiar el orden monetario que parece imponer Ezequiel. En segundo lugar y, al optar por no disputar significados y usos del dinero de forma directa con su pareja, Patricia transita la situación de "lidiar" con Natalia como una oportunidad para transmitirle valores familiares y morales como "ayudar en la casa”, a "la familia” y, a partir de las cuales ella "entienda" que las cosas son así.

En la situación de Patricia observamos que, estando en una situación mucho más desfavorable de poder y autoridad que la que detenta Marcelo, decide desplazar una estrategia que no implique una confrontación directa con Ezequiel. En este sentido, Patricia decide redistribuir obligaciones familiares y morales con Natalia, ocultando de esta manera que decide sobre el dinero que está última debería percibir pero que lo hace para cuidarla o por su porvenir: "ser alguien en la vida”.

\section{Palabras finales}

Desde que empecé a cobrar el PEC (Programa de Empleo Comunitario) que me lo tomaron para sacar en el 'Tano Muebles', acá en (Avenida) Centenario. Yo empecé con el recibo del plan de 150, eso y el DNI. Me daban... un nebulizador saque primero. Después una bicicleta para ellos (por los hijos), después los roperos, los colchones, después la tele, después la heladera, cocina, y así. Lavarropa, secarropa, todo me lo saque a crédito. (Extracto entrevista a beneficiara de la Asignación Universal por Hijo, habita en un asentamiento precario del partido de Avellaneda).

Cómo reflejan este extracto de entrevista y las restantes escenas de este artículo, los programas de transferencia monetaria condicionada se convirtieron en políticas centrales de la expansión del mercado de consumo entre los sectores de bajos recursos. También este material etnográfico muestra que ha sido a nivel de los hogares donde se conectaron las nuevas oportunidades del crédito al consumo con la expansión de ingresos provenientes del estado. No ha sido un diseño del estado, de "arriba hacia abajo", cómo la monetización de las políticas sociales se expandió como una vía hacia la financiarización del consumo. Por el contrario, fue una adaptación activa y creativa de los miembros de los sectores populares quienes acomodaron sus prácticas y relaciones 
sociales permitiendo está expansión. Esta perspectiva permite interpretar que los programas de transferencia monetaria condicionada tuvieron un rol central en la configuración de una nueva infraestructura monetaria del mundo popular que conecta familias, mercados y estado.

El antropólogo James Ferguson (2015) llamo la atención sobre el desafío político que pone en juego la expansión de los programas de transferencia monetaria condicionada como nuevo modelo de protección social vinculado al mercado y al consumo. Para Ferguson entramos en una nueva era de protección social que plantea el desafío de considerar sus consecuencias políticas. El argumento de este artículo encuentra en esta discusión un punto menos advertido y dejado de lado por Ferguson. Su antropología política le presta poca atención a cómo el dinero existe realmente en la vida de las personas.

Los programas de transferencia monetaria condicionada son tecnologías monetarias arraigadas en la vida social de las clases populares. Están necesariamente orientadas a poner en juego las relaciones de poder que configuran los vínculos entre cónyuges, padres e hijos, y otros vínculos que no exploramos en este texto pero que son centrales para comprender la dimensión política de estos programas. Desde nuestra óptica, la discusión de Ferguson no puede dejar de lado una sociología que explore las conexiones entre dinero, moral y poder. Esta perspectiva permite preguntarse por los efectos distributivos no sólo desde un punto de vista cuantitativo sino desde un punto de vista de las relaciones sociales que se están produciendo a partir de estos programas.

En este artículo damos algunos indicios de nuestra perspectiva. Analizamos cómo el orden social familiar (la autoridad y estatus de sus miembros) está enraizado en una dinámica monetaria conectada con el dinero de los programas de transferencia monetaria condicionada y las oportunidades de consumo que permite. Esta interpretación supuso vincular el dinero, la moral y el poder dentro de un marco analítico basado en el concepto de capital moral. A través de este concepto pudimos ver cómo el dinero jerarquiza moralmente a las personas $\mathrm{y}$, por lo tanto, circula produciendo relaciones de poder.

Nos propusimos poner en funcionamiento esta "caja de herramientas" conceptuales que permite comprender cómo el uso del dinero de los programas de transferencia monetaria condicionada para participar en el mercado de consumo produce mucho más cosas en la vida cotidiana de las personas que funcionar unicamente como un medio de pago sin consecuencias morales y políticas. 


\section{Referencias}

ANSES. La asignación universal por hijo para protección social. Documento del Observatorio de la Seguridad Social, $2012<$ http://observatorio.anses.gob.ar/ documentos-trabajo.php>.

BANCO MUNDIAL. Transferencias monetarias condicionadas: reduciendo la pobreza actual y futura. Washington, DC: Banco Mundial, 2009.

BARRIENTOS, Armando; HULME; David; HANLON, Joseph. Just give money to the poor: the development revolution from the global south. Brooks World Poverty Institute, 2008.

BLANC, Jerome. Usages de l'argent et pratiques monétaires. In: Philippe Steiner; François Vatin. Traité de sociologie économique. Paris: PUF, 2009. p. 649-688.

BOURDIEU, Pierre. Méditations pascaliennes. Paris: Seuil, 1997.

CAMERON, Maxwell A.; HERSHBERG, Eric (orgs.). Latin America's left turn: politics, policies and trajectories of change. Boulder: Lynne Rienner, 2010.

CECCHINI, Simone; MADARIAGA, Aldo. Programas de transferencias condicionadas: balance de la experiencia reciente en América Latina y El Caribe. Cuadernos de la Cepal, n. 95, 2011.

CEPAL. Base de datos de programas de protección social no contributiva en América Latina y el Caribe. 2016 <http://dds.cepal.org/bdptc/\#esCESE>.

CRUCES, Guillermo; MORENO, Juan Martins; RINGOLD, Dena; ROFMAN, Rafael. (eds.). Los programas sociales en Argentina hacia el bicentenario. Buenos Aires: Banco Mundial, $2008<$ http://siteresources.worldbank.org/ARGENTINAINSPANISHEXT/ Resources/Losprogramassocialesenargentinahaciabicentenario.pdf $>$.

DODD, Nigel. The social life of money. Nueva Jersey: Princeton University Press, 2014.

FERGUSON, James. Give a man a fish: reflections on the new politics of distribution. New York: Duke University Press, 2015.

GUYER, Jane Soft currencies, cash economies, new monies: past and present. Proceedings of the National Academy of Sciences of the United States of America, v. 109, n. 7, p. 2214-2221, $2012<10.1073$ /pnas.1118397109>.

HORNES, Martín. Controversias en torno a la construcción pública del dinero. Cuadernos de Antropología Social, n. 42, p. 55-71, $2015<\mathrm{http}: / /$ revistascientificas. filo.uba.ar/index.php/CAS/article/view/2301>.

HORNES, Martín. Transferencias condicionadas y sentidos plurales: el dinero estatal en la economía de los hogares argentinos. Revista Antípoda, n. 18, p. 61-83, 2014 $<10.7440$ /antipoda18.2014.04>.

KURODA, Akinubo. Concurrent but non-integrable currency circuits: complementary relationships among monies in modern China and other regions. Financial History Review, n. 15, p. 17-36, $2008<10.1017 /$ S0968565008000036>.

LAVINAS, Lena. $21^{\text {st }}$ Century welfare. New Left Review, n. 84, p. 5-40, 2013. 
LEVITSKY, Steven; ROBERTS, Kenneth M. (orgs.). The resurgence of the Latin American left. Baltimore: John Hopkins University Press, 2011.

MARX, Karl. Capital: a critique of political economy. Penguin London, 1976.

POLANYI, Karl. The great transformation: the political and economic origins of our time. Boston: Beacon Press, 2001.

STAMPINI, Marco; TORNAROLLI, Leopoldo. The growth of conditional cash transfers in Latin America end the Caribbean: did they go too far? Bonn, Institute foe the Study of Labor (IZA), $2012<$ https://publications.iadb.org/handle/11319/1448> (1으. mar. 2017).

SIMMEL, Georg. Philosophie de l'argent. París: Presses Universitaires de France, 1996.

SKOUFIAS, Emmanuel; PARKER, Susan. Conditional cash transfers and their impacts on child work and schooling: evidence from the Progresa Programa in Mexico. Washington: International Food Policy Research Institute, $2001<$ http://www. ifpri.org/>.

THERET, Bruno (orgs.). La monnaie dévoilée par ses crises. Paris: Éditions de l'EHESS, 2007.

VILLATORO, Pablo. Programas de transferencias monetarias condicionadas: experiencias en América Latina. Revista de la Cepal, n. 86, p. 87-101, 2005.

WILKIS, Ariel. The moral power of money: morality and economy in the poor people life. Stanford: Stanford University Press, 2017 (en prensa).

ZELIZER, Viviana A. How I became a relational economic sociologist and what does that mean? Politics \& Society, v. 40, n. 2, p. 145-174, $2012<10.1177 /$ $0032329212441591>$.

ZELIZER, Viviana A. El significado social del dinero. Buenos Aires: Fondo de Cultura Económica, 2011.

ZELIZER, Viviana A. Circuits in economic life. In: Viviana Zelizer (org.). Economic lives: how culture shapes the economy. Princeton: Princeton University Press, 2010. p. 344-354.

Recibido el: 3 ago. 2016

Aprobado el: 23 dic. 2016

Autor correspondiente:

Ariel Wilkis

Idaes

Avenida Roque Saenz Peña 832 - 7to Piso

CP C1035AAP - Buenos Aires, Argentina 